\title{
Focus Question based Inquiry Guided Learning for the Attainment of Course Learning Outcomes
}

\author{
R.S Vaddi \\ Department of Information Technology, V.R Siddhartha Engineering College, Vijayawada, India \\ Email: syam.radhe@gmail.com
}

\begin{abstract}
B.S Yalamanchili
Department of Computer science \& Engineering, VNR Vignana Jyothi Institute of Technology Hyderabad, India Email: bhanusree_y@vnrvjiet.in
\end{abstract}

K.R Anne

Department of Information Technology, V.R Siddhartha Engineering College, Vijayawada, India Email: raoanne@gmail.com

\begin{abstract}
Teaching and learning Methodologies in technical and engineering education has high impact on attainment of Graduate attributes. Studies have proved that class room teaching with mere usage of Black board (BB) and audio visual presentations doesn't effectively involve the student completely in learning. Also evaluation and assessment with midterm exams and end term exams may not give the complete picture of student learning progress. In fact in today's outcome based education the attainment of course learning outcomes require student centered teaching learning procedures and a continuous evaluation procedure. In this paper Focus question based Inquiry based learning an active teaching learning procedure also student centered is discussed. Also how this method is used for continuous assessment is also explained. It is successfully implemented to under graduate and post graduate students of Computer science and Information technology of engineering college, and the results are presented.
\end{abstract}

Index Terms - Inquiry Guided Learning (IGL), Course Learning Outcome, student centered learning, focus question.

\section{INTRODUCTION\&RELATED WORK}

Conventional teaching learning process has its own limitations [1] [2] and does not acquiring the requirements needed by the recent decade engineering education [3] [4]. Majority (80 - 95\%) of the class time occupancy only by lectures and lack of student participation are the main reasons for this. As the system is evolving through outcome based [5], in spite of class room teaching [5] there is a demand for activity based learning [6], where student participation is the key issue. In this era several pedagogy [7] methods were recently introduced. The present paper describes the outcomes [8] and assessment [9] from the learning science [10] project, "Inquiry guided learning (IGL) in Computer engineering". IGL combines effective learning practices in ways that are synergistic. In IGL, teams of learners (typically 3-5) work on scripted activities and investigations designed to help them construct knowledge $\&$ understand concepts. The major features of IGL include:

- Inquiry based student interaction

- Active and more interactive learners

- No dropouts in students

- Possibility for continuous Assessment

- Intermittent formative feed back

- Concept building

- Participative and team learning

Further IGL helps students to progress through the recall of information to higher order of thinking such as understanding, applying, analyzing, evaluating and creating. It is found that especially IGL in computing education is more desired because it is quite different [11] from the other engineering disciplines in acquisition of knowledge, principles, methods, tools and applications. Computing education includes:

- IGL and related approaches have strong potential in CS, since they encourage students to interact with and understand content rather than just trying to memorize everything.

- IGL helps students to develop problem-solving and teamwork skills, and also encourages students to collaborate and learn from each other rather than focusing on an instructor.

- IGL improves student attitudes and develops thinking and writing skills that is why it is recommended as a teaching method to improve learning in computing.

The inputs for the present project are taken from ITCS 1002: Data Structures using C++, a course focused on 
object oriented programming and basic data structures at department of Information Technology, V.R. Siddhartha Engineering College, India. This course has access to students with different knowledge levels in different disciplines such as vocational diploma, bachelors/master in mathematics, physics and electronics. This course is choosen for analysis because it is mandatory for both the undergraduate and graduate programs and knowledge acquired in this course has measurable influence on other courses in the program.

The motivation to experiment the present project is from the important IGL form like Process Oriented Guided Inquiry Learning (POGIL) ([12], [13]). In POGIL, teams of learners (typically $3-5$ ) work on scripted inquiry activities and investigations designed to help them construct their own knowledge, often by modeling the original processes of discovery and research. The teams follow processes with specific roles, steps, and reports. This will help towards individual responsibility and meta-cognition. POGIL has been used extensively in chemistry and other disciplines, including CS POGIL activities focus on core concepts and encourage a deep understanding of the course material while developing higher-order thinking skills [14] Studies have found that POGIL significantly improves student outcomes.

The project set out to develop a set of IGL activities and evaluate their effectiveness compared to traditional approaches to teaching and learning. The logical flow of the procedures can be shown in figure-1. It consists of 4 major set of tasks which includes different sub tasks.

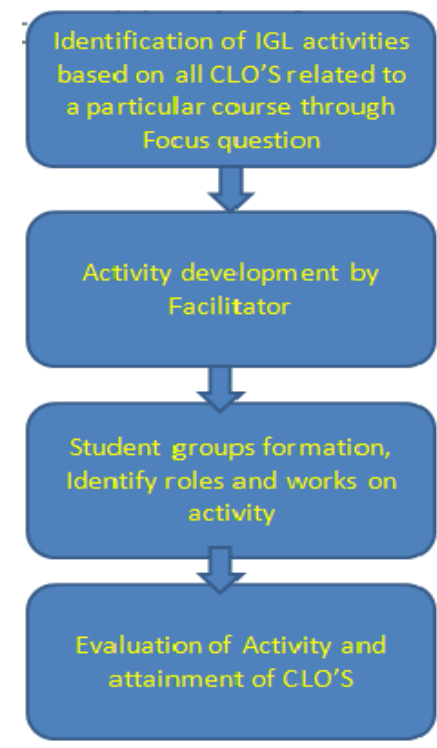

Fig.1. Stepwise procedure in performing IGL activities

\section{IGL PROCESS}

Generally a bachelor/master's program is designed with curriculum of different courses. Each course has separate course learning outcomes CLO's [15]. These can describe what the learner will know and be able to do by the end of a course Course learning out comes for the course Data Structures using $C++$ for the current project are below.

- CLO-1: Ability to distinguish Object oriented programming from declarative and procedural ones.

- CLO-2: Implementation of stacks, queues and linked lists, trees, and their applications.

- CLO-3: Ability to decide the appropriate data type and data structure for a given problem.

- CLO-4: Ability to select the best algorithm to solve a problem by considering various problem characteristics

Focus question and concept map [16] are the best tools to subdivide and understand each CLO. Focus question is a type of question that clearly specifies the problem or issue. This type of questions will engage the learners to work towards activity based learning for clear understanding the subject matters. Focus question based on CLO- 1 is,

What is object oriented programming; how does it differ from procedural oriented programming in problem solving, syntax, features etc..

Concept map is a type of graphic organizer that helps students to organize and represent knowledge of a subject. The main idea can be broken down into specific topics. Concept maps are able to resolve the focus questions. Every concept map responds to a focus question, and a good focus question can lead to a much richer concept map. Fig 2 shows a sample Concept maps for a sample focus question. IGL activities are to be created in accordance with focus question. Two IGL activities are identified for the present focus question as shown in table-1.

Table 1. IGL Tasks for the focus question

\begin{tabular}{|l|l|}
\hline Task & Concept covered \& Outcome \\
\hline IGL 1 & $\begin{array}{l}\text { Data Types \& Control Structures } \\
\text { Exemplify different data types } \\
\text { and learn control structures and } \\
\text { suitable applications }\end{array}$ \\
\hline IGL 2 & $\begin{array}{l}\text { Difference between Procedural \& } \\
\text { Object Oriented Programming } \\
\text { Identify key syntax differences } \\
\text { between C and C++. }\end{array}$ \\
\hline
\end{tabular}

\section{Activity in practice}

In the very beginning facilitator will give oral introduction about the topic chosen. This may be done using simple power point presentation or by any of the learning tools. In the project, we have used focus question based concept to give the overview of the topic.

The students work on the activity during class time with the presence of facilitator. The dominant mode of instruction is not lecture or instructor-cantered; the instructor served predominantly as a facilitator for enabling student learning.

In brief each session activity is done like below 
- Work through an initial information set and series of questions as a team. Prepare a presentation of answers to the class.

- Compare and discuss answers as a class to arrive at a consensus. Practice a quick way to get everyone's attention (raise hand, chime, flash lights, rhythmic clap, etc.)

- Have students report out at specified points throughout the activity, such as at the stop signs or keys, not just at the end.

- Group Consensus strategy - Have each group write an answer/ summary/ report of a particular point or question on board. If all the answers aren't in agreement, give each group 2 minutes to agree to change their answer or to defend their reasoning. Continue until the Class reaches full consensus.

- Evaluate the level of understanding of concepts along with team's group dynamics.

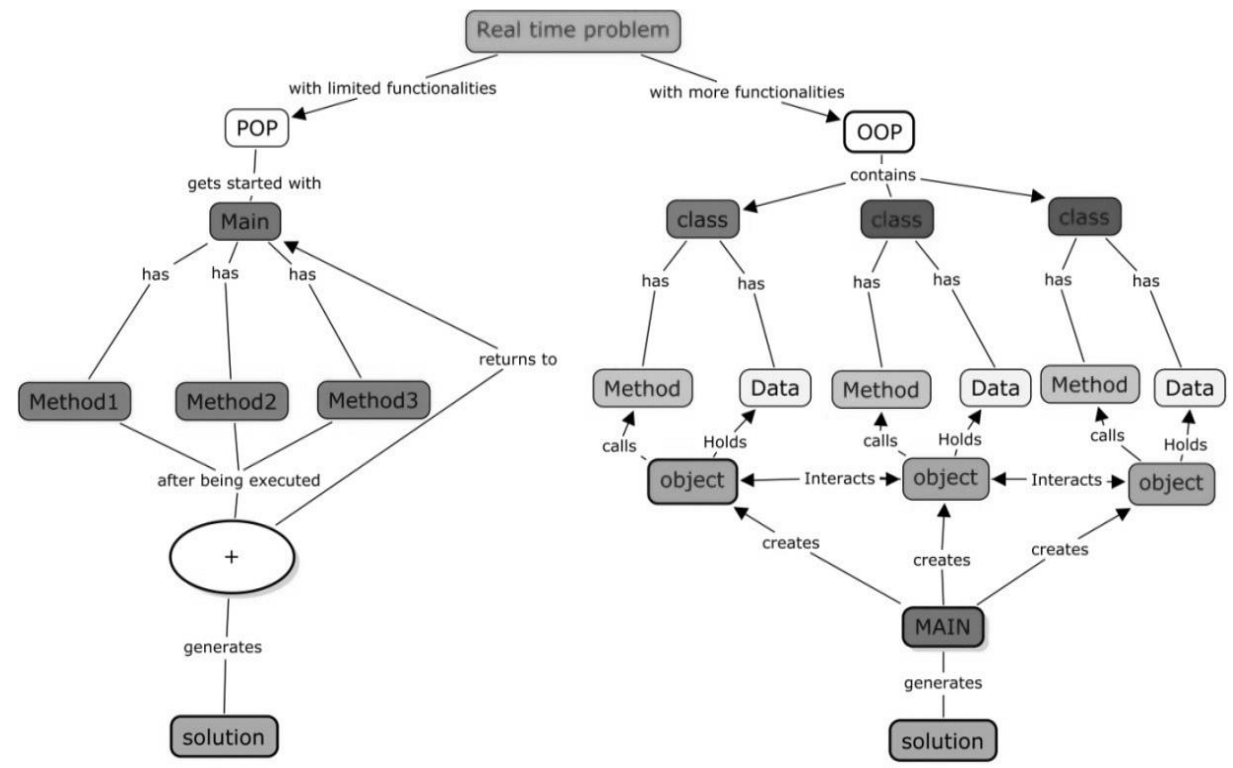

Fig.2. Concept Map for the Focus question

\section{Groups formation among students}

The main criterion followed in group formation is to combine students with difference in their skills. Each group is composed of three to four students.

Total 36 students participated in this activity. Students were divided into 9 groups, of 4 in each group. Names of the people in the groups with a specific description of their roles are like below.
Speaker: Talks to instructor and other team of people.

Manager: keeps track of time and makes sure everyone contributes to the activity appropriately.

Presenter: Presents the answers and represent the team of people.

Recorder: records all answers \& questions and prepare summary.

Table 2. GL Tasks and description

\begin{tabular}{|c|c|c|}
\hline Task & Concept covered & Outcome \\
\hline IGL 1 & Data Types \& Control Structures & $\begin{array}{l}\text { Exemplify different data types and learn } \\
\text { control structures with suitable engineering } \\
\text { type of applications }\end{array}$ \\
\hline IGL 2 & $\begin{array}{l}\text { Difference between Procedural \& Object } \\
\text { Oriented Programming }\end{array}$ & $\begin{array}{l}\text { Understand the use of programming and } \\
\text { Identify key syntax differences between C } \\
\text { and C++ for the better way of implementing. }\end{array}$ \\
\hline IGL 3 & Pointers \& Constructors & $\begin{array}{l}\text { Implement pointers and constructers in } \\
\text { various examples and different scenarios. }\end{array}$ \\
\hline IGL 4 & $\begin{array}{l}\text { Functions, Recursive Functions, \& Virtual } \\
\text { Functions }\end{array}$ & $\begin{array}{l}\text { Explore the concept of modularity in } \mathrm{C}++ \text { and } \\
\text { use recursion to solve some gaming problems }\end{array}$ \\
\hline IGL 5, 6 & Searching and sorting & $\begin{array}{l}\text { Develop and compare the comparison-based } \\
\text { search algorithms and sorting algorithms. }\end{array}$ \\
\hline IGL 7,8 & Stack, Queue & $\begin{array}{l}\text { Exemplify and implement stack, and queue } \\
\text { ADT to manage the memory using } \\
\text { static/dynamic allocations. }\end{array}$ \\
\hline IGL 9 & Linked lists & $\begin{array}{l}\text { Identify necessity of List ADT and implement } \\
\text { it for other data structures }\end{array}$ \\
\hline
\end{tabular}




\section{OUTCOME ASSESSMENT}

After completion of the task each group needs to present the work done. Finally, every task is concluded by the evaluation [14]. Once all the questions have been presented and defended, students should use the IGL activity as notes for the course. We emphasize to students that IGLs are excellent study materials to use in preparing for end unit assessments.

The formative assessment of IGL activity in this project was done in two ways: using rubrics and quizzes. A rubric (Table-III) is an authentic assessment tool used to measure students' work. It is a scoring guide that seeks to evaluate a student's performance based on the sum of a full range of criteria rather than a single numerical score.

The outcome assessment is done in direct and indirect methods. In direct method, the student's activity sheets, presentation and the end examination are considered. In the indirect method, students were posed the survey questions and given an option to drop their comments in a box on their experiences with IGL. Indirect assessment method is conducted in the duration of the course and also at the end of the course. Student participation in the surveys is observed to be more than $85 \%$.

\section{Indirect assessment}

Apart from the comment based feedback, a survey is also executed at the end of the course to analyze the impact of all IGL activities.

Students had four choices (agree, satisfactory, neutral, disagree) to respond to four questions. Indirect assessment performed for the present case is attained up to $90 \%$. The sample questions with followed rubric used in this assessment process is shown below.

Table 3. Sample Rubric for IGL Tasks

\begin{tabular}{|l|l|}
\hline Specific criteria & *Rating \\
\hline Comprehensively synthesizes POP and OOP & $/ \mathbf{5}$ \\
\hline Performance in matching activity & $/ \mathbf{5}$ \\
\hline $\begin{array}{l}\text { Comprehensively synthesizes applications and } \\
\text { difference between POP and OOP. }\end{array}$ & $/ \mathbf{5}$ \\
\hline $\begin{array}{l}\text { Performance in home assignment } \\
\text { Begins with summary of the activity, ends with } \\
\text { summary of questions. }\end{array}$ & $/ \mathbf{5}$ \\
\hline $\begin{array}{l}\text { Team member roles and time management. } \\
\text { providing required information. }\end{array}$ & $/ \mathbf{5}$ \\
\hline $\begin{array}{l}\text { Total Rating and overall comments } \\
\text { Rating for the above rubric is: }\end{array}$ & \\
\hline
\end{tabular}

* Rating for the above rubric is:

1-poor 2-satisfactory 3-good 4-verygood 5-Exemplary

\section{Direct assessment}

The direct assessment of the student's performance is measured continuously through their activities and with a semester end examination. Continuous assessment is done mainly based on the activity end evaluation rubric. Rubrics that were developed for the present IGL activity to assess student performance by clearly indicating the two criteria's like specific to the concept and general skills with their ratings for total 30 marks. As shown in Table 1. There also exists of one column for comments which can be useful in the review and feedback. Continuous assessment through rubric is clearly explained in section 2 as Tasks after the activity.

The results obtained by the continuous assessment and semester end assessment appeared almost similar. A survey is done by taking votes from students for different activities ( 1 to 8 different tests) performance with IGL and normal teaching without IGL. Finally average difference called $\mathrm{p}$ value of $\mathrm{t}$ is measured. [18].The corresponding diagram is shown in Fig-5

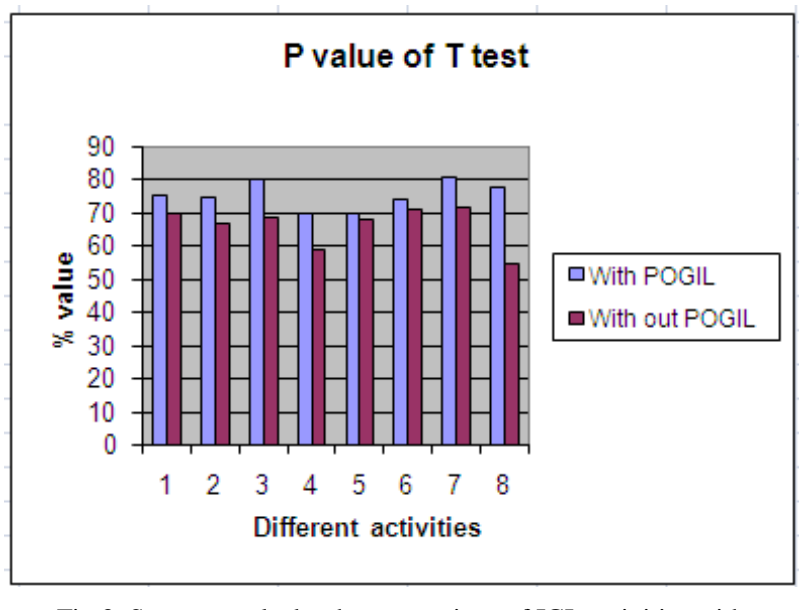

Fig.3. Survey results by the comparison of IGL activities with traditional teaching

\section{CONCLUSION}

Due to high demand for student centric learning, Outcome-based education (OBE) has become recurring education reform model. Generally Graduation or postgraduation programs consists of set of courses and respective course learning outcomes (CLO). The main objective is to attain CLo's. This project demonstrated Inquiry Guided Learning (IGL) as a tool in the attainment process through focus questions.

IGL is performed by the introduction of critical activities on the courses. These activities are highly correlate with CLO's and focus question. All the activities are executed in the class room and assessed student performance. Feedback from the student also analyzed in order to improve the process for further courses. Our major goal for the future is to conduct of the experiments with different groups of students, and variety of courses. Develop the course content for computing subjects like Data structures, C language, JAVA and DBMS in the IGL model. We also plan to use 
a scoring rubric that measures important factors in the solution process

\section{REFERENCES}

[1] B.S Koduru, R. S. Vaddi, and K. R. Anne Inquiry based guided learning to enhance interest and higher order thinking in engineering graduates 1 st international Conference on 'Transformations in Engineering Education (ICTIEE) published in SPRINGER LNS Jan2014.

[2] D. M. Hanson, Instructor's Guide to Process-Oriented Guided-Inquiry Learning. Pacific Crest, 2006.

[3] C. Kussmaul, "Process oriented guided inquiry learning for soft computing," Proc. of the International Conference on Advances in Computing \& Communication, Kochi, India, 2011.

[4] C. Kussmaul, "Process oriented guided inquiry learning for computer science", Proc. of the ACM SIGCSE Technical Symposium on Computer Science Education, Raleigh, NC, USA, 2012.

[5] C. Kussmaul, Queues \& Stacks, Searching, Inheritance, Project Scheduling (4 POGIL activities) [Online] 2011. Available: http://cspogil.org.

[6] C. M. Lewis, N. Titterton, and M. Clancy, "Developing students' self-assessment skills using lab-centered instruction," J. Comput. Sci. Coll., vol. 26, no. 4, pp. 173180, Apr. 2011.

[7] R. S. Moog and J. N. Spencer, Eds., Process-Oriented Guided Inquiry Learning (POGIL). Oxford University Press, USA, 2008.

[8] Learning and Teaching Programming: A Review and Discussion Anthony Robins, Janet Rountree, Nathan Rountree Computer Science Education Vol. 13, Iss. 2, 2003

[9] Robert F. Schneider March 7, 2012] Why Concept Maps? Available.http://www.ic.sunysb.edu/Class/che133/concept maps/Example/MapOverview.html.

[10] Alberto J. Cañas \& Joseph D. Novak March 7, 2012] Constructing your first concept map Available http://cmap.ihmc.us/docs/ConstructingAConceptMap.htm 1.

[11] Designing contributing student pedagogies to promote students' intrinsic motivation to learn Geoffrey L. Herman Computer Science Education Vol. 22, Iss. 4, 2012.

[12] P value of T tests Central Virginia Governor's School for Science and Technology Lynchburg 2003.

[13] http://www.cvgs.k12.va.us:81/DIGSTATS/main/inferant/ d_tdist.htmFarida Bouarab Dahmani Automated Evaluation of Learner's Solutions Expressed in a
Graphical Language: Application to the Relational Databases Domain I.J.Modern Education and Computer Science, Vol.7, No. 1, January 2015.

[14] H anson, D. M. (2006). Instructor's Guide to ProcessOriented Guided-Inquiry Learning. Pacifi c Crest.

[15] 24july2012). The Centre for Teaching Excellence, University of Waterloo, Canada Available: http://cte.uwaterloo.ca/teaching_resources/tips/rubrics.ht $\mathrm{ml}$.

[16] William Peirce Designing Rubrics for Assessing Higher Order Thinking workshop presented at AFACCT Howard Community College Columbia, MD, on January 13, 2006.

[17] Helen H. Hu. 2012. Using POGIL to teach students to be better problem solvers (abstract only). In Proceedings of the 43rd ACM technical symposium on Computer Science Education (SIGCSE '12). ACM, 672672.DOI=10.1145/2157136.2157395.http://doi.acm.org/1 $0.1145 / 2157136.2157395$.

[18] J. D. Gobert and B. C. Buckley, "Introduction to modelbased teaching and learning in science education," International Journal of Science Education, vol. 22, pp. 891-894, 2000/09/01 2000.

\section{Author Profiles}

R.S.Vaddi is an assistant professor in Information Technology at V.R Siddhartha Engineering College Vijayawada. In teaching he has been focusing on applying student centric methods for the subjects like Data structures and programming. His research includes Computer vison, algorithm analysis and active teaching.

B.S. Yalamanchili is an assistant professor in Computer Science Engineering at VNR Vignan Jyothi Institute of Technology. In teaching she has been focusing on applying pedagogical and student centric Reaserch interests include speech processing, emotion detection and computer vision.

Dr. Techn. K.R. Anne is Professor in Information technology and Dean Academics in VR Siddhartha engineering college. In teaching his passion includes experimenting active teaching methodologies in DBMS and Distributed computing. His research includes Computer vison, Speech processing.

How to cite this paper: R.S Vaddi, B.S Yalamanchili, K.R Anne,"Focus Question based Inquiry Guided Learning for the Attainment of Course Learning Outcomes", IJMECS, vol.7, no.7, pp.48-52, 2015.DOI: 10.5815/ijmecs.2015.07.06 